\title{
Tyrosinase Positive
}

National Cancer Institute

\section{Source}

National Cancer Institute. Tyrosinase Positive. NCI Thesaurus. Code C128846.

Indicates that tyrosinase expression has been detected in a sample. 